\title{
Caste-based social inequalities and childhood anemia in India: results from the National Family Health Survey (NFHS) 2005-2006
}

Priya Vart ${ }^{1}$, Ajay Jaglan ${ }^{2}$ and Kashif Shafique $3,4^{*}$

\begin{abstract}
Background: Caste is one of the traditional measures of social segregation in India and differs from other indicators as it is both, endogamous and hereditary. Evidence suggests that belonging to lower castes exposes one to social inequalities and affects health adversely. We examined the association of caste with childhood anemia in India and explored the effect modifying role of adult education and household wealth.

Methods: A cross-sectional analysis of National Family Health Survey (NFHS) data of 43,484 children aged 6-59 months was performed. Poisson regression analysis was conducted to study the association between caste and childhood anemia accounting for various maternal, child, and household related variables. Caste was categorized as "other caste" (least disadvantageous), "other backward caste", "scheduled tribe" and "scheduled caste" (most disadvantageous). Anemia was defined as mild (hemoglobin level 7-11 g/dL), moderate (hemoglobin level 5-7 $\mathrm{g} / \mathrm{dL}$ ) and severe (hemoglobin level $<5 \mathrm{~g} / \mathrm{dL}$ ).
\end{abstract}

Results: We found that children in scheduled caste had higher risk of having anemia [mild anemia: RR $=1.10,95 \%$ $\mathrm{Cl}=1.05-1.15$; moderate anemia: $\mathrm{RR}=1.19,95 \% \mathrm{Cl}=1.14-1.24$; severe anemia: $\mathrm{RR}=1.87,95 \% \mathrm{Cl}=1.51-2.31]$ after accounting for child, maternal and household covariates including adult education and household wealth. The interaction of caste with adult education and household wealth was not statistically significant for any level of anemia. Sensitivity analyses for children born to mothers of age $\geq 18$ years at first child birth and body mass index $(\mathrm{BMI}) \geq 18.5 \mathrm{~kg} / \mathrm{m}^{2}$, resulted in similar findings.

Conclusion: Caste is an independent determinant of childhood anemia in India. The level of adult education and household wealth did not modify the association between caste and childhood anemia. The findings may be used for countering childhood anemia and it may be beneficial to target future public health actions towards disadvantageous castes in India.

Keywords: Caste, Anemia, Education, Wealth, Children

\section{Background}

The proportion of children under 5 years of age having anemia in India is among the highest in the world. The prevalence of childhood anemia has been reported as high as $70 \%$ in India [1]. Anemia is strongly associated with child morbidity and mortality [2]. Existing research on childhood anemia has mainly focused on factors like maternal age, education, height, child breastfeeding and

\footnotetext{
* Correspondence: kashif.shafique@Glasgow.ac.uk

${ }^{3}$ School of Public Health, Dow University of Health Sciences, Karachi, Pakistan ${ }^{4}$ Institute of Health \& Wellbeing, Public Health, University of Glasgow,

1-Lilybank Gardens, Glasgow, UK

Full list of author information is available at the end of the article
}

place of residence [3]. Caste is one of the traditional measure of social segregation in India and differs from other indicators in that it is both endogamous and hereditary $[4,5]$. Caste based social segregation has been linked to socioeconomic disadvantage and many adverse health outcomes $[6,7]$.

A large proportion of people of disadvantageous castes belong to low socioeconomic groups in India. Therefore, these people are generally exposed to poor living conditions, have poor diet and limited access to health care. Consequently, children born in disadvantageous castes are more likely to face infections (e.g. malaria), have iron 
deficient diet and limited availability of iron supplements which ultimately can lead to anaemia. In addition to their low socioeconomic circumstances, people in disadvantageous castes experience other adverse circumstances such as caste based discrimination. Caste based discrimination is associated with poor mental health which in turn has been shown to be associated with iron deficiency in infants [8]. Thereby, caste might be associated with anaemia independent of socioeconomic factors like education and wealth. Moreover, previous studies have also speculated about effect modification between caste and socioeconomic factors for their association with child mortality in India [9]. Unfortunately, the association between caste and childhood anemia in relation to adult education and household wealth is not well understood in India. Although a few studies has highlighted higher prevalence of childhood anemia in disadvantageous castes in India [10-14], these studies neither explored association between caste and childhood anemia independent of adult education and household wealth nor did they investigate effect modifying role of adult education and household wealth in this association.. Furthermore, previous studies were conducted on small non-representatives samples of regional populations, using non-probabilitybased sampling techniques which limited the external validities of those studies.

Therefore, we examined the association of caste based social segregation and childhood anemia while accounting for adult education and household wealth in a nationally representative sample of children under the age of 5 years in India. We further explored any effect modifying role of adult education and household wealth in the association between caste and childhood anemia.

\section{Methods}

The data for this study was drawn from the National Family Health Survey - 2005-2006 (NFHS) held in India (data released in 2008). The NFHS was conducted to establish a representative data of demographic and health indicators of national and state population of India. In particular, child and maternal health outcomes were targeted. The NFHS is similar to Demographic Health Surveys (DHS) which are operational in a large number of developing countries. Details of the survey can be found at: http://www.measuredhs.com/.

In brief, this survey included children born to the mothers aged 15-49 years since January 2000/2001 (in some states data collection started in January 2000 and while in others in January 2001). A total of 124, 385 women, from 131, 596 eligible women (response rate $94.5 \%)$ participated in the survey. Women were included from 116, 652 randomly selected households. Since January 2000/2001, 51, 555 live births (age 0 59 months) were reported. The protocol of NFHS was assessed and approved by ethics committee at the International Institute for Population Sciences, Mumbai in association with Ministry of Health, India.

\section{Study population and design}

For the present study we included singleton children aged $6-59$ months born in 29 states in India. Since hemoglobin levels were measured only for children aged $\geq 6$ months, we restricted our sample to children aged $6-59$ months $(n=43,484)$. We excluded the children with missing information on anemia levels $(n=6,277)$, caste $(n=1,973)$, adult education $(n=154)$, and other children/maternal/household covariates including birth order, mother's smoking status, mother's occupation and household wealth ( $\mathrm{n}=1,937)$, leaving a sample of 33,488 children for final analysis. In baseline characteristics, no notable differences were observed between original and final study sample (data not shown but available from authors).

\section{Caste, adult education and household wealth}

Information on caste was based on the type of caste selfreported by head of the household. Types of the castes were scheduled caste, scheduled tribes, other backward class and other caste [15].

Information on adult education was obtained from education levels of both parents. Adult education, thereby, refers to two variables i.e. maternal education and paternal education. Adult education was recorded according to the levels of education mentioned in Indian educational system i.e. no education (0 years), primary education (1-5 years), secondary education (6-10 years) and higher education (more than 10 years).

Household wealth was defined in terms of household assets and material possessions. Asset ownership is a reliable measure of wealth and living standards in India [16]. We use the wealth score provided in the NFHS 2005-2006 dataset. In this dataset, wealth score was obtained based on a combination of household characteristics including consumer durables, characteristics of the residential place and land ownership. Household characteristics were weighted according to a factor analysis procedure. Households were allocated a final household wealth score calculated from the summation of weights for each item into a linear index. Linear index was then converted into quintiles for the analysis.

\section{Anemia}

Anemia was measured from hemoglobin levels of the children aged $6-59$ months Hemoglobin levels of $7-11 \mathrm{~g} / \mathrm{dL}, 5-7 \mathrm{~g} / \mathrm{dL}$ and $<5 \mathrm{~g} / \mathrm{dL}$ were categorized as mild, moderate and severe anemia, respectively [17].

\section{Other covariates}

Child covariates included were age, gender, birth order, religion and place of residence. Birth order of the child 
was categorized into three levels of birth order i.e. less than 3,3 to 6 and more than 6 . Religion of the child was determined based on the religion of the head of the household (Hindu, Muslim, Christian, other). Place of residence was classified into rural and urban. Maternal covariates included were age at birth of first child, body mass index (BMI), marital status, smoking and occupation. The height and weight of women were measured using a solar-powered electronic (SECA) scale with a digital screen. Body mass index was calculated using the standard formula-Weight $(\mathrm{kg}) /$ Height $^{2}\left(\mathrm{~m}^{2}\right)$. Marital status of the mother was categorized as married and unmarried (including never married, divorced, widowed or separated). Smoking status was defined as nonsmokers and smokers (smoking cigarettes/bidis and/or pipe/cigar). Maternal occupation was classified into non-worker, manual worker or non-manual worker.

\section{Statistical analysis}

All analyses were conducted using STATA version 11 (StataCorp, College Station, TX, USA). A $p$-value of $<0.05$ was considered to indicate statistical significance. We used NFHS recommended specific weights that accounted for the sample weights and the multistage cluster survey sampling design. Baseline characteristics for continuous data was reported as mean (standard error). Categorical data are presented as weighted percentages with $95 \% \mathrm{CI}$. Means are compared between groups using ANOVA and proportions were compared using Pearson's chi ${ }^{2}$ test.

Since anemia was not a rare outcome in our study, we performed modified Poisson regression approach with robust error variance. This approach models the binary outcome and provide risk ratios with $95 \%$ confidence internal [18]. We did separate analyses for mild, moderate and severe levels of anemia. First we estimated the independent association of individual anemia levels with caste (model 0). Subsequently, adjustment was made for potential confounders including child (age, gender, birth order and religion) and maternal demographic factors (age at birth of first child, BMI, marital status, occupation, smoking status and place of residence) (Model 1). In order to explore whether the association between anemia and caste existed after additionally adjusting for adult education (model 2) and household wealth (model 3) individually, and together (model 4), we re-estimated the models. Effect modification between caste and adult education and then between caste and household wealth was investigated from interaction terms.

We performed sensitivity analyses to test the robustness of our findings. First, understanding the significant association between maternal age at birth of first child and child nutritional status, we re-estimated the association between caste and anemia levels only for children who were born to mothers aged $\geq 18$ years at the birth of their first child. Second, to account for disadvantage of having anemia in children born to mothers with low BMI, we repeated the analysis for children having a maternal $\mathrm{BMI} \geq 18.5 \mathrm{~kg} / \mathrm{m}^{2}$.

\section{Results}

Baseline characteristics

The baseline characteristics of the study population according to caste are presented in the Table 1. Almost one third of the study population (30.4 \%) belonged to other caste (i.e. higher caste) and one fifth $(19.3 \%)$ to the scheduled casted (lowest caste). There was no difference in the mean age of the child among different castes $(p=0.107)$. In the scheduled tribe, prevalence of overall anemia was highest $(77 \%)$ and maternal BMI was lowest $\left(19.3 \mathrm{~kg} / \mathrm{m}^{2}\right)$. Maternal smoking was similar in scheduled tribe and scheduled caste $(2.5 \%$ each). Most of the children in scheduled tribe were born in rural areas (91\%).

The distribution of adult education and household wealth in different levels of anemia is shown in Table 2 (percentages shown are the weighted percentages for survey design). Approximately $69 \%(n=21,786)$ of the study population was anemic. Of the total anemic population, $26 \%(\mathrm{n}=8,772)$ were mildly anemic, $40 \%(\mathrm{n}=12,160)$ were moderately anemic and $2.9 \%(\mathrm{n}=854)$ were severely anemic. Lowest prevalence of severe anemia (12\%) was in other backward class. Largest anemia population of children was born to un-educated mothers (45\%). Similarly, majority of mild (41\%), moderate (48\%) and severely (55\%) anemic children belonged to un-educated mothers. On contrary, in household with most prevalence of anemia (48\%), father had education up to secondary level. Same was true for mild (49\%), moderate (47\%) and severe (48 \%) levels of anemia. The prevalence of overall and severe anemia was highest in poor households $(41 \%$ and $45 \%$, respectively).

\section{Association between caste and anemia}

In univariate analysis (model 0), compared to children in other caste, children born in other backward caste, scheduled tribe and scheduled caste were associated with higher prevalence of mild, moderate and severe anemia.

The association of caste with each level of anemia existed after adjusting for childhood (age, sex, birth order, place of residence and religion) and maternal demographic characteristics (BMI, marital status, occupation and smoking status) (model 1).

Further, adjustment for adult education and household wealth, individually (model 2 and model 3, respectively) and simultaneously (model 4) resulted in similar findings (Table 3).

Moderating effect of adult education and household wealth There was no significant interaction between caste and adult education for association with mild, moderate or 
Table 1 Baseline characteristics of study population according to caste ${ }^{a}$

\begin{tabular}{|c|c|c|c|c|c|}
\hline \multirow[b]{2}{*}{ Child characteristics } & \multicolumn{5}{|l|}{ Caste } \\
\hline & Other caste & Other backward class & Scheduled tribe & Scheduled caste & $p$-value \\
\hline$(\mathrm{N}=33,488)$ & $(n=10,185)$ & $(n=11,819)$ & $(n=5,015)$ & $(n=6,469)$ & \\
\hline Age (months) & $32.7(0.19)$ & $32.8(0.14)$ & $32.7(0.26)$ & $32.5(0.19)$ & 0.107 \\
\hline Male & $53(52-55)$ & $54(53-55)$ & $52(50-54)$ & $52(50-53)$ & 0.003 \\
\hline Birth order & & & & & $<0.001$ \\
\hline$<3$ & $80(79-82)$ & $73(71-74)$ & $64(62-67)$ & $71(69-73)$ & \\
\hline 3 to 6 & $15(14-17)$ & $22(21-23)$ & $29(27-31)$ & $23(21-24)$ & \\
\hline$>6$ & $4.0(3.3-5.0)$ & $5.6(4.9-6.4)$ & $6.8(5.4-8.1)$ & $6.1(5.1-7.2)$ & \\
\hline Anemia $(\mathrm{Hb}<11 \mathrm{~g} / \mathrm{dL})$ & $64(63-66)$ & $70(69-71)$ & $77(75-79)$ & $73(71-74)$ & $<0.001$ \\
\hline \multicolumn{6}{|l|}{ Maternal characteristics } \\
\hline Age at first birth (years) & $20.0(0.07)$ & $19.1(0.05)$ & $18.7(0.09)$ & $18.7(0.07)$ & $<0.001$ \\
\hline Body mass index $(\mathrm{kg} / \mathrm{m} 2)$ & $20.4(0.09)$ & $19.7(0.05)$ & $19.5(0.07)$ & $19.3(0.09)$ & $<0.001$ \\
\hline Married & $99(98-100)$ & $99(98-100)$ & 97 (96-98) & $98(97-99)$ & 0.005 \\
\hline Smoking (present) & $1.0(0.4-1.6)$ & $1.7(1.2-2.1)$ & $2.5(1.4-3.7)$ & $2.5(1.8-3.2)$ & $<0.001$ \\
\hline Education & & & & & $<0.001$ \\
\hline No education & $32(29-35)$ & $53(51-54)$ & $69(66-72)$ & $58(56-60)$ & \\
\hline Primary & $14(12-15)$ & $14(13-15)$ & $12(11-14)$ & $14(13-16)$ & \\
\hline Secondary & $44(42-47)$ & $29(28-31)$ & $17(15-20)$ & $25(24-27)$ & \\
\hline Occupation & & & & & $<0.001$ \\
\hline Non worker & 77 (76-79) & $59(58-61)$ & $33(30-36)$ & $56(54-59)$ & \\
\hline Manual worker & $17(16-19)$ & $37(35-38)$ & $64(61-67)$ & $38(36-41)$ & \\
\hline Non manual worker & $5.3(4.6-6.0)$ & $4.0(3.5-4.5)$ & $3.3(2.5-4.1)$ & $5.4(4.5-6.2)$ & \\
\hline Higher & $10(9-11)$ & $3.7(3.2-4.2)$ & $1.2(0.7-1.7)$ & $2.2(1.7-2.6)$ & \\
\hline \multicolumn{6}{|l|}{ Other characteristics } \\
\hline Residence (rural) & $66(64-68)$ & $76(75-78)$ & 91 (89-93) & $77(75-80)$ & 0.035 \\
\hline Father's education & & & & & $<0.001$ \\
\hline No education & $20(18-23)$ & $27(26-29)$ & $47(44-50)$ & $32(30-35)$ & \\
\hline Primary & $13(12-14)$ & $15(14-16)$ & $17(15-19)$ & $17(16-19)$ & \\
\hline Secondary & $49(47-52)$ & $49(47-51)$ & $32(29-35)$ & $44(42-47)$ & \\
\hline Higher & $17(16-19)$ & $8.5(7.7-9.2)$ & $4.2(3.2-5.1)$ & $6.1(5.2-6.9)$ & \\
\hline \multicolumn{6}{|l|}{ Household wealth } \\
\hline Poor & $30(27-32)$ & $47(45-49)$ & $77(75-80)$ & $59(56-61)$ & $<0.001$ \\
\hline Middle & $19(17-20)$ & $23(21-24)$ & $12(10-14)$ & $19(17-20)$ & \\
\hline Rich & $51(49-54)$ & $30(29-32)$ & $10(8.3-12)$ & $23(21-25)$ & \\
\hline Religion & & & & & $<0.001$ \\
\hline Hindu & $65(62-69)$ & $84(82-86)$ & 87 (84-89) & $91(90-93)$ & \\
\hline Muslim & $30(26-34)$ & $15(13-17)$ & $1.3(0.6-1.9)$ & $1.7(1.0-2.4)$ & \\
\hline Sikh & $1.2(0.8-1.5)$ & $1.0(0.6-1.3)$ & $7.6(5.8-9.4)$ & $1.1(0.7-1.6)$ & \\
\hline Christian & $2.8(2.3-3.3)$ & $0.4(0.2-0.6)$ & 0.0 & $2.1(1.5-2.7)$ & \\
\hline Other & $0.7(0.4-1.0)$ & $0.2(0.1-0.3)$ & $4.5(3.0-6.0)$ & $3.7(2.6-4.7)$ & \\
\hline
\end{tabular}

${ }^{a}$ Continuous variables are presented as mean (standard errors) and categorical variables as percentages

severe anemia (Maternal education: $p=0.41, p=0.35$ and $p=0.27$; Paternal education: $p=0.23, p=0.17$ and $p=0.41$ for mild, moderate and severe anemia respectively). Similarly no interaction was observed between caste and household wealth $(p=0.97, p=0.39$ and $p=0.57$ for mild, moderate and severe anemia 
Table 2 Distribution of caste, adult education and household wealth in levels of anemia ${ }^{a}$

\begin{tabular}{|c|c|c|c|c|}
\hline \multirow[b]{2}{*}{ Characteristics } & \multicolumn{4}{|c|}{ Anemia levels } \\
\hline & Overall & Mild & Moderate & Severe \\
\hline $\bar{N}$ & $21786(69)$ & $8772(26)$ & $12160(40)$ & $854(2.9)$ \\
\hline \multicolumn{5}{|l|}{ Caste } \\
\hline Other caste & $6,024(28)$ & $2,682(31)$ & $3,163(26)$ & $247(29)$ \\
\hline Other backward caste & $7,917(36)$ & $3,098(35)$ & $4,494(37)$ & $106(12)$ \\
\hline Scheduled tribe & $3,292(15)$ & $1,329(15)$ & $1,857(16)$ & $322(28)$ \\
\hline Scheduled caste & $4,556(21)$ & $1,663(19)$ & $2,646(22)$ & $179(21)$ \\
\hline \multicolumn{5}{|l|}{ Maternal education } \\
\hline No education & $9,906(45)$ & $3,608(41)$ & $5,832(48)$ & $466(55)$ \\
\hline Primary education & $3,186(15)$ & $1,293(15)$ & $1,768(15)$ & $125(15)$ \\
\hline Secondary education & $7,474(34)$ & $3,300(38)$ & $3,941(32)$ & $233(27)$ \\
\hline Higher education & $1,220(6)$ & $571(7)$ & $619(5)$ & $30(4)$ \\
\hline \multicolumn{5}{|l|}{ Father's education } \\
\hline No education & $5,835(27)$ & $2,084(24)$ & $3,472(29)$ & 279 (33) \\
\hline Primary education & $3,392(16)$ & $1,372(16)$ & $1,899(16)$ & $121(14)$ \\
\hline Secondary education & $10,410(48)$ & 4,293 (49) & $5,704(47)$ & $413(48)$ \\
\hline Higher education & $2,149(10)$ & $1,023(12)$ & $1,085(9)$ & $41(5)$ \\
\hline \multicolumn{5}{|l|}{ Household wealth } \\
\hline Poor & $9,026(41)$ & $5,694(44)$ & $4,367(36)$ & $383(45)$ \\
\hline Middle & 4,486 (21) & $2,679(21)$ & $2,482(20)$ & $197(23)$ \\
\hline Rich & $8,274(38)$ & $4,641(35)$ & $5,311(44)$ & 274 (32) \\
\hline
\end{tabular}

${ }^{a}$ Analysis has been adjusted for survey specific weights

${ }^{a}$ Estimates are presented as percentages

respectively). In stratified analyses on adult education and household wealth, findings remained consistent with overall results (data not shown).

\section{Sensitivity analyses}

First, repeating the analysis for children born to mothers having age $\geq 18$ years at the birth of their first child (sample size; $n=24,526$ for severe anemia analysis; $n=23,955$ for moderate anemia; $n=15,436$ for mild anemia) did not change the overall associations (Table 4). Furthermore, we excluded the children of mothers having a $\mathrm{BMI}<18.5 \mathrm{~kg} / \mathrm{m}^{2}$ (sample size; $\mathrm{n}=24,369$ for severe anemia analysis; $\mathrm{n}=23,807$ for moderate anemia; $\mathrm{n}=15,400$ for mild anemia) and re-estimated the association between caste and anemia levels (Table 5). This also did not provide any evidence of a convincing difference.

\section{Discussion}

Our results suggest that the caste based social segregation is associated with mild, moderate and severe levels of anemia in India. These associations existed even after accounting for demographic factors including adult education and household wealth. Furthermore, stratification on adult education and household wealth, and using interaction on multiplicative scale for caste, the effect of adult education and household wealth did not differ among different castes.

A number of studies have investigated the caste related health disparities in India. Studies have linked scheduled castes and scheduled tribes with higher comorbidities [13], mortality [15], stunting and wasting in children [19], child mortality [20] and higher prevalence of childhood anemia [21]. Most studies were conducted on regional, small, convenience-based samples except a study by Van de Poel E et al. [19] which mainly focused on child stunting and wasting but not anemia. Study by Nayar KR, briefly reported the prevalence of childhood anemia using nationally representative NFHS 1998-1999 data (ref.). In present study, using more recent data (NFHS 2005-2006), we examine the association between caste and childhood anemia independent of adult education and household wealth. In addition, we investigate effect modifying role of parental education and wealth in the association between caste and childhood anemia. To our knowledge, this is the first study to investigate the association of caste with childhood anemia independent of adult education and household wealth in a nationally representative sample of children younger than 5 years in India.

Health disparities exist across various other population subgroups also in developed countries. For instance, low birth weight and infant mortality is more strongly associated with African-American race than other racial/ethnic groups in the United States (US) [22]. Similar to disadvantageous castes in India, racial/ethnic minorities (except Asian-Americans) in the US usually belong to low socioeconomic groups and face discrimination. Studies suggest socioeconomic status, racial discrimination and genetic factors as among the potential causes of poor health in African-Americans [23]. However, unlike race/ethnicity, there is no reported genetic difference in castes in India and therefore is unlikely to be a cause of disproportionate childhood anemia in disadvantageous caste in India.

Most of people of disadvantageous cates belong to low socioeconomic groups in India. Low socioeconomic status may affect the prevalence of anemia via several pathways including 1) poor living and working conditions, 2) adverse health behaviors such as maternal smoking poor dietary habits and 3) limited health car use and limited health literacy which might influence their noncompliance with use of iron supplements. In our data also, more women were smokers in disadvantageous castes than in other caste. Thereby, these pathways might explain the association between caste and childhood anemia. However, in our study, after adjusting for socioeconomic factors (i.e. adult education and household wealth) the association between caste and childhood 
Table 3 Association of caste with levels of childhood anemia

\begin{tabular}{|c|c|c|c|c|c|c|}
\hline \multirow[b]{3}{*}{ Anemia levels } & & \multicolumn{5}{|l|}{ Caste } \\
\hline & & \multirow{2}{*}{$\begin{array}{l}\text { Other caste }{ }^{a} \\
\text { RR }(95 \% \text { Cl) }\end{array}$} & \multirow{2}{*}{$\begin{array}{l}\text { Other backward class } \\
\text { RR }(95 \% \mathrm{Cl})\end{array}$} & \multirow{2}{*}{$\begin{array}{l}\text { Scheduled tribe } \\
\text { RR }(95 \% \mathrm{Cl})\end{array}$} & \multicolumn{2}{|l|}{ Scheduled caste } \\
\hline & & & & & RR $(95 \%$ Cl) & $p$-trend \\
\hline \multirow[t]{5}{*}{ Mild } & Model 0 & 1 & $1.08(1.04-1.13)$ & $1.15(1.10-1.22)$ & $1.15(1.10-1.21)$ & $<0.001$ \\
\hline & Model 1 & 1 & $1.09(1.04-1.13)$ & $1.26(1.19-1.73)$ & $1.17(1.11-1.22)$ & $<0.001$ \\
\hline & Model 2 & 1 & $1.05(1.01-1.09)$ & $1.18(1.11-1.25)$ & $1.10(1.05-1.16)$ & $<0.001$ \\
\hline & Model 3 & 1 & $1.08(1.04-1.16)$ & $1.17(1.10-1.24)$ & $1.12(1.07-1.18)$ & $<0.001$ \\
\hline & Model 4 & 1 & $1.07(1.02-1.11)$ & $1.15(1.08-1.22)$ & $1.10(1.05-1.15)$ & $<0.001$ \\
\hline \multirow[t]{5}{*}{ Moderate } & Model 0 & 1 & $1.16(1.12-1.21)$ & $1.25(1.20-1.31)$ & $1.28(1.23-1.34)$ & $<0.001$ \\
\hline & Model 1 & 1 & $1.15(1.11-1.20)$ & $1.36(1.29-1.43)$ & $1.26(1.21-1.32)$ & $<0.001$ \\
\hline & Model 2 & 1 & $1.11(1.07-1.15)$ & $1.24(1.18-1.31)$ & $1.19(1.14-1.24)$ & $<0.001$ \\
\hline & Model 3 & 1 & $1.16(1.11-1.20)$ & $1.25(1.19-1.32)$ & $1.23(1.18-1.29)$ & $<0.001$ \\
\hline & Model 4 & 1 & $1.13(1.09-1.17)$ & $1.23(1.16-1.29)$ & $1.19(1.14-1.24)$ & $<0.001$ \\
\hline \multirow[t]{5}{*}{ Severe } & Model 0 & 1 & $1.46(1.22-1.76)$ & $1.26(0.99-1.60)$ & $2.07(1.72-2.52)$ & $<0.001$ \\
\hline & Model 1 & 1 & $1.48(1.23-1.79)$ & $1.62(1.23-2.13)$ & $2.09(1.70-2.57)$ & $<0.001$ \\
\hline & Model 2 & 1 & $1.36(1.12-1.64)$ & $1.38(1.04-1.83)$ & $1.84(1.49-2.27)$ & $<0.001$ \\
\hline & Model 3 & 1 & $1.46(1.21-1.77)$ & $1.47(1.11-1.96)$ & $2.01(1.63-2.48)$ & $<0.001$ \\
\hline & Model 4 & 1 & $1.35(1.12-1.63)$ & $1.38(1.04-1.84)$ & $1.87(1.51-2.31)$ & $<0.001$ \\
\hline
\end{tabular}

${ }^{\mathrm{a}}$ Other caste was considered as reference category

Model 0 Univariate analysis

Model 1 Model $1+$ Child age, sex, birth order, religion, maternal age at first child birth, maternal BMI

marital status, residence, occupation and smoking status

Model 2 Model 2 + adult education (maternal and father's education)

Model 3 Model $2+$ household wealth

Model 4 Model $2+$ adult education (maternal and father's education) and household wealth

(Shown are the risk ratio with $95 \%$ confidence interval of developing mild, moderate and severe anemia among other backward castes, scheduled caste and scheduled tribe keeping other caste as reference category)

anemia was still significant. It suggests that independent of socioeconomic status there are other pathways that link caste to childhood anemia. We believe that caste based discrimination might be one such pathway that associate caste with childhood anemia. It should be noted that NFHS 3 do not have data on caste based discrimination and investigating role of caste based discrimination in the association between caste and childhood anemia is beyond the aims of this study. Future studies should investigate this issue.

After independence in 1947, affirmative government actions promoted reservations in government educational institutes and jobs for disadvantageous caste to ensure better education and job opportunity. Such opportunities improved the level of educational attainment and economic gains in disadvantageous caste [24]. The adult education and household wealth are known determinants of health. Adult education and household wealth influence health in a number of ways including access to better health care, improved health literacy and life style habits. Therefore, adult education and household wealth can be considered as important effect modifiers in association between caste and health conditions like childhood anemia. However, in our results, caste reservation for ensuring better education and economic opportunities could not completely mitigate the inequalities in occurrence of

Table 4 Association of caste with levels of childhood anemia for children born to mothers aged $\geq 18$ years at first child birth ${ }^{a}$

\begin{tabular}{|c|c|c|c|c|c|}
\hline \multirow[b]{3}{*}{ Anemia levels } & \multicolumn{5}{|l|}{ Caste } \\
\hline & Other caste ${ }^{a}$ & Other backward class & Scheduled tribe & Scheduled caste & \\
\hline & RR $(95 \%$ Cl) & RR $(95 \% \mathrm{Cl})$ & RR $(95 \%$ Cl) & RR $(95 \%$ Cl) & $p$-trend \\
\hline Mild & 1 & $1.05(1.01-1.10)$ & $1.13(1.05-1.23)$ & $1.09(1.03-1.16)$ & $<0.001$ \\
\hline Moderate & 1 & $1.12(1.08-1.13)$ & $1.22(1.15-1.30)$ & $1.20(1.13-1.25)$ & $<0.001$ \\
\hline Severe & 1 & $1.34(1.07-1.67)$ & $1.50(1.05-2.14)$ & $2.01(1.56-2.56)$ & $<0.001$ \\
\hline
\end{tabular}

${ }^{a}$ Model has been adjusted for child, maternal and household covariates including adult education and household wealth

(Shown are the risk ratio with $95 \%$ confidence interval of developing mild, moderate and severe anemia among other backward castes, scheduled caste and scheduled tribe keeping other caste as reference category) 
Table 5 Association of caste with levels of childhood anemia for children born to mothers with BMI $\geq 18.5 \mathrm{~kg} / \mathrm{m}^{\mathrm{a}}$

\begin{tabular}{|c|c|c|c|c|c|}
\hline & \multicolumn{5}{|l|}{ Caste } \\
\hline & Other caste $^{a}$ & Other backward class & Scheduled tribe & Scheduled caste & \\
\hline Anemia levels & RR $(95 \% \mathrm{Cl})$ & RR $(95 \% \mathrm{Cl})$ & $\mathrm{RR}(95 \% \mathrm{Cl})$ & $\mathrm{RR}(95 \% \mathrm{Cl})$ & $\overline{p \text {-trend }}$ \\
\hline Mild & 1 & $1.06(1.02-1.12)$ & $1.14(1.06-1.22)$ & $1.13(1.07-1.20)$ & $<0.001$ \\
\hline Moderate & 1 & $1.09(1.04-1.14)$ & $1.20(1.13-1.28)$ & $1.20(1.13-1.26)$ & $<0.001$ \\
\hline Severe & 1 & $1.32(1.05-1.67)$ & $1.34(1.09-1.59)$ & $1.81(1.39-2.34)$ & $<0.001$ \\
\hline
\end{tabular}

${ }^{a}$ Model has been adjusted for child, maternal and household covariates including adult education and household wealth

(Shown are the risk ratio with $95 \%$ confidence interval of developing mild, moderate and severe anemia among other backward castes, scheduled caste and scheduled tribe keeping other caste as reference category)

childhood anemia between different castes. In order to explore the effect modifying role of adult education and household wealth, we also stratified analysis by these factors and did not observe differential association of caste for different levels of adult education and household wealth. One of the important finding in this study was that there was no consistent linear relationship between caste and childhood anemia. This might suggest that the amount of social disadvantage do not increase linearly in other backward class, scheduled tribe and scheduled caste in relation to other castes.

Strengths of this study are the use of detailed information on a number of relevant covariates from large nationally representative data. Our study has certain limitations. Because of data constrains we had limited information on some of the relevant covariates. There was unavailability of information on maternal psychological factors that are known determinant of childhood anemia. We also lacked information on access to healthcare which is linked with malnutrition in childhood [19]. Since in Indian settings, place of residence (rural/urban) is used as a proxy of access to health care, we accounted for place of residence. Therefore, limited information on health care access is less likely to affect our results. Caste reservation policy in India started well before the collection of data on demographic and health indicators of the population. Therefore we were not able to compare the gains (if any), resulting from such policies in mitigating caste based inequalities in prevalence of childhood anemia. Eventually it is difficult to conclude whether caste reservation has helped in countering health related disadvantage in lower caste.

This study has important public health implications. As our results suggested that there is a higher risk of anemia in disadvantageous caste and these caste based disparities in childhood anemia exist independent of adult education and household wealth public health approaches tailored to disadvantageous castes irrespective of their educational and wealth status might be more beneficial in countering childhood anemia in India. Eleventh five year plan for anemia control for children in India can also be benefited from targeted IFA (Iron-Folic Acid) supplements to disadvantageous caste. Furthermore, future studies should investigate causal pathways that link caste to childhood anemia.

\section{Conclusion}

Caste is an independent determinant of childhood anemia in India even after accounting for other social advantages including adult education and household wealth. Future public health actions targeted to disadvantaged castes might be more beneficial in countering childhood anemia in India.

\section{Competing interests}

The authors declare that they have no competing interests

\section{Authors' contributions}

PV and AJ conceived the idea of this research study. PV conducted the statistical analysis, PV, AJ and KS were involved in interpretation of results. PV AJ written the initial draft of this manuscript. KS has contributed in developing research idea and added important intellectual content during manuscript drafting or revision. All authors contributed and approved the final draft.

\section{Acknowledgements}

We are grateful to the program and organizers of Demographic Health Surveys for providing and assisting in management of data.

\section{Author details}

'Department of Health Sciences, Community and Occupational Medicine, University Medical Center Groningen, University of Groningen, Groningen, The Netherlands. 'Department of Paediatrics, Medical College Guwahati, Guwahati, India. ${ }^{3}$ School of Public Health, Dow University of Health Sciences, Karachi, Pakistan. ${ }^{4}$ Institute of Health \& Wellbeing, Public Health, University of Glasgow, 1-Lilybank Gardens, Glasgow, UK.

Received: 15 September 2014 Accepted: 27 May 2015

Published online: 05 June 2015

\section{References}

1. Kotecha PV. Nutritional anemia in young children with focus on Asia and India. Indian J Community Med. 2011;36(1):8.

2. International Institute for Population Sciences, vol. 1: National Family Health Survey (NFHS-3), 2005-06 India; 2007.

3. Subramanian S, Ackerson LK, Smith GD, John NA. Association of maternal height with child mortality, anthropometric failure, and anemia in India. JAMA. 2009:301(16):1691-701.

4. Mohindra K, Haddad S, Narayana D. Women's health in a rural community in Kerala, India: do caste and socioeconomic position matter? J Epidemiol Community Health. 2006;60(12):1020-6.

5. Dumont L, Sainsbury M. Homo hierachius: the caste system and its implications. London: Weidenfeld \& Nicolson; 1970. 
6. Deshpande A. Caste at birth? Redefining disparity in India. Rev Dev Econ. 2001;5(1):130-44.

7. Cochrane SH, Leslie J, O'Hara DJ. Parental education and child health: intracountry evidence. Health Policy Educ. 1982;2(3):213-50.

8. Coe CL, Lubach GR, Shirtcliff EA. Maternal stress during pregnancy predisposes for iron deficiency in infant monkeys impacting innate immunity. Pediatr Res. 2007;61:520-4.

9. Singh-Manoux A, Dugravot A, Smith GD, Subramanyam M, Subramanian S. Adult education and child mortality in India: the influence of caste, household wealth, and urbanization. Epidemiology (Cambridge, Mass). 2008;19(2):294.

10. Sudhagandhi B, Sundaresan S, William W, Prema A. Prevalence of anemia in the school children of Kattankulathur, Tamil Nadu, India. Int J Nutr Pharmacol Neurol Dis. 2011;1 (2):184.

11. Sidhu S, Kumari K, Uppal M. Prevalence of anemia in schedule caste preschool children of Punjab. Indian J Med Sci. 2002;56(5):218.

12. Prabhakar SJ, Gangadhar M. Prevalence of Anaemia in Jenukuruba Primitive Tribal Children of Mysore District. Karnataka Anthropologist. 2009:11(1):49-51.

13. Haddad S, Mohindra KS, Siekmans K, Màk G, Narayana D. "Health divide" between indigenous and non-indigenous populations in Kerala, India: Population based study. BMC Public Health. 2012;12(1):390.

14. Arlappa N, Laxmaiah A, Balakrishna N, Harikumar R, Kodavanti MR, Gal Reddy $C$, et al. Micronutrient deficiency disorders among the rural children of West Bengal, India. Ann Hum Biol. 2011;38(03):281-9.

15. Subramanian S, Nandy S, Irving M, Gordon D, Lambert H, Smith GD. The mortality divide in India: the differential contributions of gender, caste, and standard of living across the life course. Am J Public Health. 2006;96(5):818.

16. Filmer $D$, Pritchett LH. Estimating wealth effects without expenditure data - or tears: An application to educational enrollments in states of india*. Demography. 2001;38(1):115-32.

17. Organization WH. Worldwide prevalence of anaemia 1993-2005: WHO global database on anaemia. 2008.

18. Zou G. A modified poisson regression approach to prospective studies with binary data. Am J Epidemiol. 2004;159(7):702-6.

19. Van de Poel E, Speybroeck N. Decomposing malnutrition inequalities between Scheduled Castes and Tribes and the remaining Indian population. Ethnicity Health. 2009;14(3):271-87.

20. Dommaraju P, Agadjanian V, Yabiku S. The pervasive and persistent influence of caste on child mortality in India. Popul Res Policy Rev. 2008;27(4):477-95.

21. Nayar K. Social exclusion, caste \& health: a review based on the social determinants framework. Indian J Med Res. 2007;126(4):355.

22. Arias $E$, MacDorman MF, Strobino DM, Guyer B. Annual summary of vital statistics-2002. Pediatrics. 2003;112(6):1215-30.

23. Collins Jr JW, David RJ, Handler A, Wall S, Andes S. Very low birthweight in African American infants: the role of maternal exposure to interpersonal racial discrimination. Am J Public Health. 2004;94(12):2132-8.

24. Borooah VK, Dubey A, lyer $\mathrm{S}$. The effectiveness of jobs reservation: caste, religion and economic status in India. Dev Chang. 2007;38(3):423-45.

\section{Submit your next manuscript to BioMed Central and take full advantage of:}

- Convenient online submission

- Thorough peer review

- No space constraints or color figure charges

- Immediate publication on acceptance

- Inclusion in PubMed, CAS, Scopus and Google Scholar

- Research which is freely available for redistribution 